\title{
Switching Characteristics of Two Series-Connected Triggered Vacuum Gaps
}

\author{
Student Member Hazairin Samaulah (Niigata University) \\ Member Kouichi Itagaki (Niigata University) \\ Member Hiroshi Kitamura (Niigata University) \\ Member Akira Sugawara (Niigata University)
}

\begin{abstract}
Switching characteristics of two series-connected triggered vacuum gaps (TVGs) have been investigated experimentally. Each TVG was mechanically connected in series to be four connection modes.

The withstand voltage of two series-connected TVGs was about 2 times greater than that of a single TVG. It was also observed that there was no effect of the connection modes against the withstand voltage of two series-connected TVGs when the impulse voltage polarity was positive or negative.

The similar case was also shown in a single TVG.

The polarity effect to the switching time and the grounding were pronounced. When the lower TVG was grounded and both nonholed electrodes were positive, the switching time was short and nearly constant ( $1.4 \mu$ as at 5 to $30 \mathrm{kV}$ ). Conversely, when both nonholed electrodes were negative, the switching time was long. When the polarity of each nonholed electrode was different, the switching time was long. However the polarity effect to the switching time decreased.

When two series-connected TVGs was floating, it showed the shortest switching time and nearly constant $(0.3 \mu \mathrm{s}$ at 5 to $25 \mathrm{kV})$.
\end{abstract}

Key words: Two series-connected triggered vacuum gaps, Switching time, Withstand voltage

\section{Introduction}

The performance of high voltage heavy current pulse power generator is determined by the characteristics of the switches. The switches are of various types (1)-(1) and as demand grows for high quality pulse power, the switch specification becomes more stringent. A major goal of research and development are an improvement in performance of switches.

Compared to air trigatron (5) (6) and the other gap switch, triggered vacuum gap (7) showed good switching characteristics over a wide working voltage range from several kilovolts to several tens kilovolts with no adjustment of the gap length.

For that reason, applications to the impulse voltage chopping system ${ }^{(8)}$ (9) and an overvoltage protection device (10) (1) with wide working voltage range are expected when triggered vacuum gap is emplo- yed in place of air trigatron.

The withstand voltage of a single triggered vacuum gap is usually several tens kilovolts. The withstand voltage of the gap must be increased in high voltage circuit.

For this purpose, various methods have been attempted by the research workers including increasing of the gap length from 25 to 100 mon and equalizing electric field strength with several shields placed near the electrodes ${ }^{(7)}$ or by introducing intermediate electrodes ${ }^{(12)}$. However these methods were costly because they needed a large-sized gap as well as complicated electrodes configuration. Therefore in this research we have concentrated our attention on the series connection of some small TVGs to increase the withstand voltage (13) (14).

We have obtained some results concerning the series connection of some small TVGs. 




Fig. 1. Schematic diagram of triggered vacuum gap.

(1) The withstand voltage of multistage triggered vacuum gaps increased with the number of stages.

(2) The switching time of multistage triggered vacuum gaps decreased with increasing the trigger currents.

(3) The arcing time of multistage triggered vacuum gaps was shorter than that of one stage TVG.

The arcing time, however, could be prolonged by using long time constant $\mathrm{RC}$ discharge circuit for trigger current.

(4) The chopped impulse wave was generated by applying multistage triggered vacuum gaps to the impulse voltage chopping gap.

The switching characteristics of a single TVG were strongly influenced by the electrode polarity (15)(20). The switching time of a single TVG was short when the nonholed main electrode polarity was positive. However the switching characteristics of two series-connected TVGs have not been adequately investigated.

When two triggered vacuum gaps are mechanically connected in series, four connection modes exist. Specifically, the following items have been examined: $<1>$ The withstand voltage of two series-connected triggered vacuum gaps,

(2) The effect of the main electrode polarity to the switching time, and

<3> The effect of the grounding to the switching time.

The polarity effect to the switching time was pronounced when the lower TVG was grounded and both nonholed main electrodes were positive or negative. When two series-connected TVGs were floating, their switching time were short and nearly constant $(0.3 / \mathrm{s}$ at 5 to $25 \mathrm{kV}$ ).

\section{Experimental circuit and procedure}

Two sealed-off triggered vacuum gaps are connected in series to improve the withstand voltage.

The schematic digram of the triggered vacuum gap is shown in Fig. 1 . Using a conventional vacuum interrupter (21), the trigger electrode is placed at the center of the stationary main electrode.

The insulating vacuum envelop ( $83 \mathrm{~mm}$ in outside $\mathrm{dia}^{-}$ meter and $200 \mathrm{~mm}$ in length) is made from alumina $\left(\mathrm{Al}_{2} \mathrm{O}_{3}\right)$, the gap between two main electrodes can be varied up to $20 \mathrm{~mm}$ by changing the position of nonholed electrode with the help of bellows. The main electrodes on rods of $30 \mathrm{~mm}$ in diameter are made from the alloy of silver-tungsten-carbide ( $\mathrm{Ag}-\mathrm{WC})$. The main electrode material $\mathrm{Ag}-\mathrm{WC}$ is produced in vacuum by the infiltration of $\mathrm{Ag}$ into the sintered WC skeleton whose powder size is several microns. One of main electrodes has a central hole of $8 \mathrm{~mm}$ in diameter ; inside this hole a molibdenum (Mo) trigger pin of $6 \mathrm{~mm}$ in diameter is mounted. The holed electrode and the trigger pin are insulated with alumina. The pressure inside the chamber is about $1.3 \times 10^{-5} \mathrm{~Pa}$.

Fig. 2 shows four modes of mechanical connection of two series-connected triggered vacuum gaps. Eight 




(A)

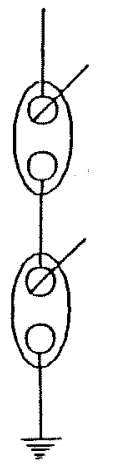

(I)

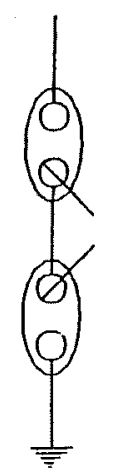

(C)



(D)
Fig. 2. Four mechanical connection modes of two series-connected triggered vacuum gaps.

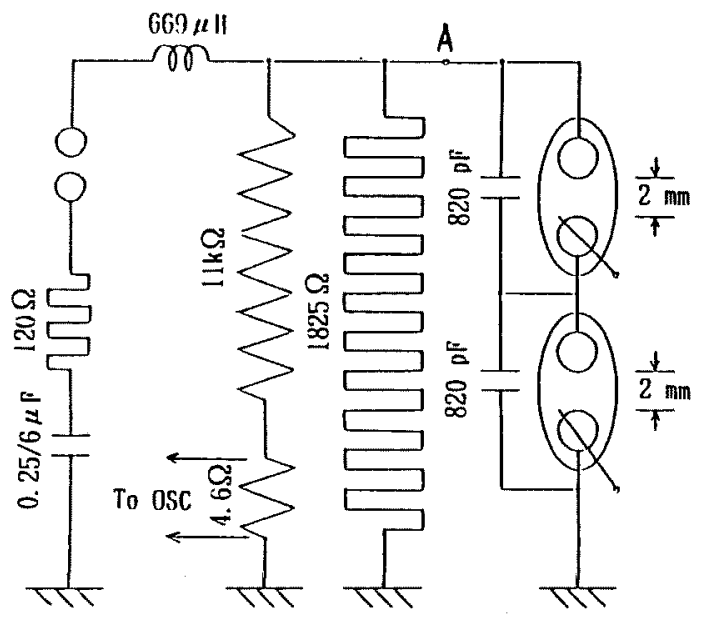

Fig. 3. Impulse breakdown voltage test circuit.

operation modes are obtained by changing the main electrode polarity on the upper TVG when the lower TVG is grounded and the polarity of trigger electrode is kept constant. The polarities of both nonholed electrodes are the same as in Fig. 2(A) and (B), while the polarity of each nonholed electrode is different in Fig. 2(C) and (D).

Fig. 3 shows the experimental circuit for the measurement of the withstand voltage. To obtain un if orm voltage applied to the gaps, capacitor dividers are connected to each gap. The lower TVG is grounded. The trigger electrodes were open circuited during the experiment for all of the connection modes as shown in Fig. 2.

The standard impulse voltage waveform applied is $\pm 1.2 / 48$ us. The $50 \%$ flashover voltage ( $50 \% \mathrm{FOV})$ or the withstand voltage of two series-connected TVG were determined by up and down method ${ }^{(22)}$ with vol-

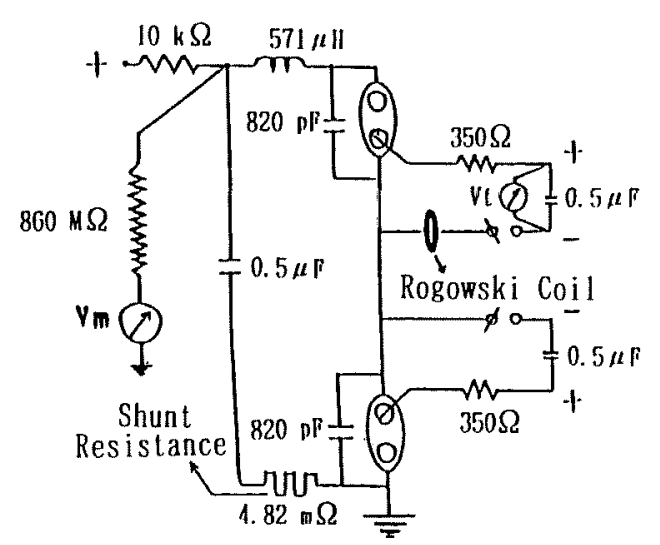

Fig. 4. Test circuit for measuring switching time.

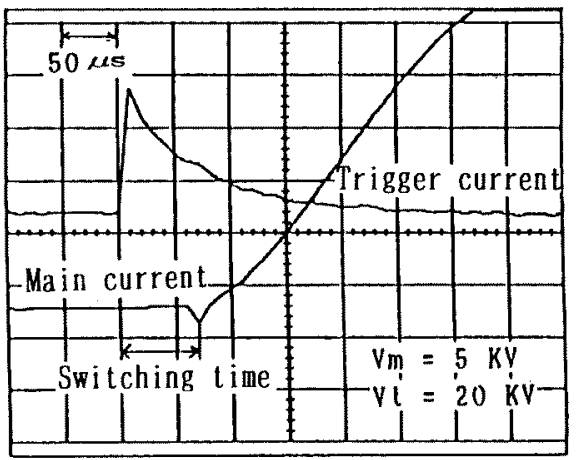

Fig. 5. Switching time between the initiation of the trigger current and the initiation of the main current.

tage step width of $4.6 \mathrm{kV}$, the voltage being applied 40 times. The breakdown of the vacuum gaps was confirmed with observing the output voltage waveform through oscilloscope.

Measuring the switching time of two series-connected TVGs is carried out by using the connection modes and the test circuit as shown in Fig. 2 and Fig. 4. The lower TVG is grounded.

During this experiment, the charging voltage of trigger capacitor and the gap length of each TVG were kept unchanged to $20 \mathrm{kV}$ and $2 \mathrm{~mm}$ respectively. Trigger electrodes were triggered with two positive trigger pulses. To supply dc high voltage across vacuum gaps in the range $5-35 \mathrm{kV}$, a simple charging circuit was used.

Switching time as shown in Fig. 5 was obtained based on the time lag between the initiation of trigger current and the initiation of the main current measured by using a Rogowski coil and shunt resistance, which are connected to a oscilloscope. Then, 


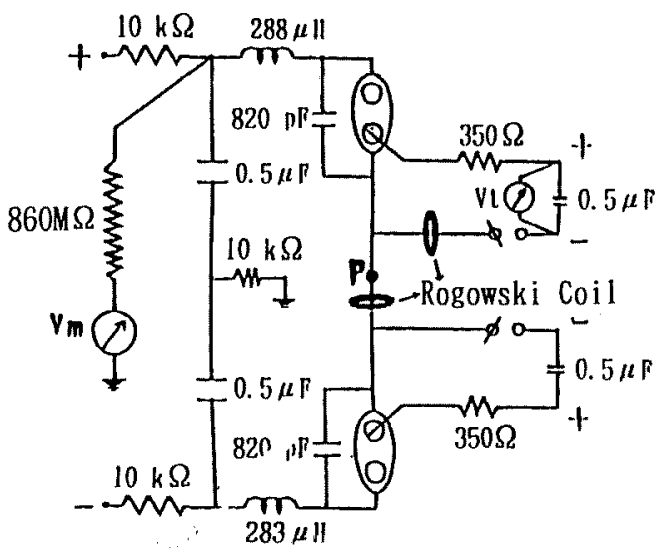

Fig. 6. Test circuit for measuring switching time to the grounding effect.



Fig. 7. Waveforms of trigger current and main current when the neutral point of two seriesconnected TVGs was grounded.

the measurement was carried out as many as ten trials on each the main voltage under the same condition for obtaining the accuracy of measurement.

The average of ten trials for a particular condition is taken as such switching time. The value of the scatter of the switching time in all the cases is within $25-649 \%$.

Fig. 6 shows the test circuit for measuring switching time with respect to the grounding effect. The charging voltage of trigger capacitor and the gap length of each TVG were also kept unchanged to $20 \mathrm{kV}$ and $2 \mathrm{~mm}$ respectively. Trigger electrodes of two series-connected triggered vacuum gaps were triggered with two positive trigger pulses. To supply dc high voltage across vacuum gaps in the range $5-25 \mathrm{kV}$, a voltage doubler charging circuit was used.

Switching time was obtained in the same manner as above. Fig. 7 shows waveforms of the trigger cur- rent and main current when the neutral point $P$ in Pig. 6 was grounded.

\section{Experimental results and discussion \\ 3. 1 The withstand voltages of two series- connected triggered vacuum gaps}

The working voltage range of TVG should be large enough. The withstand voltage of TVG gives the upper limit of working voltage.

The edge effects of trigger electrode in each TVG should be considered. Table 1 shows the withstand voltages of two series-connected TVGs. The withstand voltages of a single TVG is shown in Table 2. The value of the standard deviation of the $50 \%$ FOV in all the connection modes is within 13 to $18 \%$.

The differences in the $50 \%$ FOV of Table 1 for four connection modes were smaller than $7 \%$ when the positive or negative voltage was applied to the upper TVG. The withstand voltage of two series-connected TVGs was about 2 times greater than that of a single TVG. It seems, therefore, that there was no effect of the connection modes to the withstand voltage when the impulse voltage polarity was positive or negative.

Table 1. The withstand voltages of two series-connected TVGs.

\begin{tabular}{|c|c|c|}
\hline \multirow{2}{*}{ Connection modes } & \multicolumn{2}{|c|}{$50 \%$ FOV (kV) } \\
\cline { 2 - 3 } in Fig.2 & $(t)$ & $(-)$ \\
\hline (A) & 62.6 & 62.3 \\
(B) & 63.5 & 58.1 \\
(C) & 62.0 & 61.6 \\
(D) & 62.6 & 58.9 \\
\hline
\end{tabular}

$(t) /(-)$ : Impulse voltage polarity

Table 2. The withstand voltages of a single TVG.

\begin{tabular}{|c|c|c|}
\hline \multirow{2}{*}{$\begin{array}{c}\text { Connection modes } \\
\text { in Fig. } 10\end{array}$} & \multicolumn{2}{|c|}{$50 \%$ FoV $(\mathrm{kV})$} \\
\cline { 2 - 3 }$(\mathrm{S})$ & 29.0 & $(-)$ \\
\hline
\end{tabular}

$(+) /(-)$ : Impulse voltage polarity 


\section{2 The effect of the polarity to the switching time}

Based on the connection modes such as in Fig. 2, we have measured switching time of two series-connected TVGs as a function of main voltage with different polarities as shown in Fig. 8 and Fig. 9. From the measurement results can be found that ;

(1) When the polarity of both nonholed electrodes was positive, the switching time was the shortest of all and nearly constant as shown in Fig. $8(\mathrm{~A})+$ and Fig. 9(B) - . The switching time of curves (A) + and (B) - from 5 to $30 \mathrm{kV}$ were $1.4 \mu \mathrm{s}$ and $1.5 \mu \mathrm{s}$ respec- $^{-}$ tively. Conversely, when the polarity of each nonholed electrode was negative, the switching time was the longest of all and could not be operated at main voltage of less than $25 \mathrm{kV}$ as shown in Fig. 8(B)+ and Fig. 9(A)-. Thus, the polarity effect to the switching time was large in $(A)$ and (B) of the connection modes in Fig. 2 .

A similar case was also displayed in a single TVG as shown in Fig. 10. The gap length of a single TVG was 2 min. The trigger current was the same as in case of Fig. 8 or Fig. 9. The switching time of mode (S) + was shorter than that of mode (S) - .

This switching characteristics are in agreement with results of the other experiment $(16)-(19)$.

The switching times of curves $(A)+$ and $(B)-$ in Fig. 8 and Fig. 9 were 3.5 times greater than that of curve $(S)+$ in Fig. 10, while curves $(B)+$ and $(A)-$ were longer than that of curve $(S)-$ at main voltage $20 \mathrm{kV}$.

(2) When the polarities of each nonholed electrode were different, the switching time was longer than that of curves $(A)+$ and (B) - in Fig. 8 and Fig. 9. Curves $(C)+,(D)+,(C)-$ and $(D)-$ in Fig. 8 and Fig. 9 tend to decrease with increasing main voltage.

The switching time was relatively long, but the polarity effect to the switching time was relatively small in connection modes (C) and (D) in Fig. 2.

When a single TVG is triggered on the cathode, the trigger plasma expands more fast into main gaps than when it is triggered on the anode ${ }^{(20)}$. Therefore the polarity effect to the switching time occurs. After both TVGs had broke down, the total breakdown

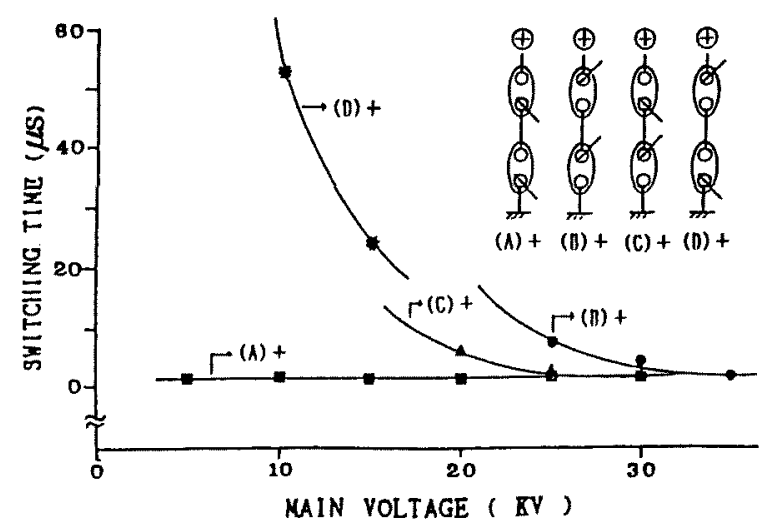

Fig. 8. Switching time as a function of main voltage when the positive voltage is applied to the upper TVG.

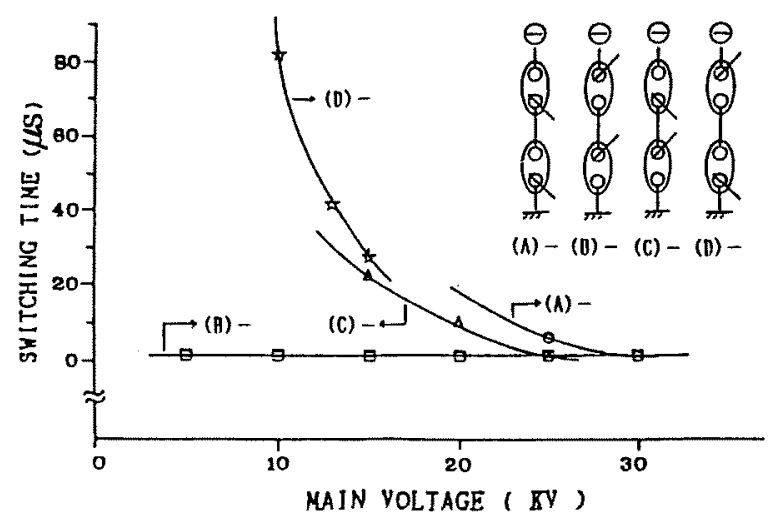

Fig. 9. Switching time as a function of main voltage when the negative voltage is applied to the upper TVG.

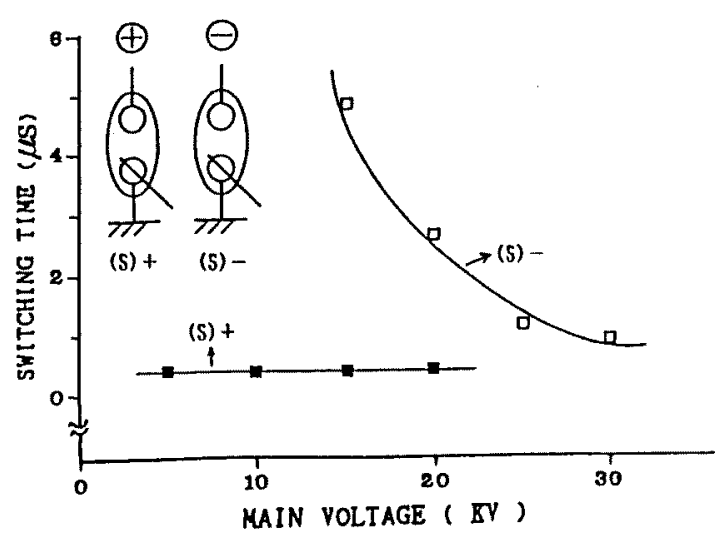

Fig. 10. Switching time as a function of main voltage of a single TVG with the different main electrode polarity.

of two series-connected TVGs occurred. Therefore the switching time of two series-connected TVGs was 
longer than that of a single TVG.

In comparison with a single TVG, two series-connected TVGs have two advantages :

(1) the withstand voltage is high, and

(2) the polarity effect to the switching time tends to decrease when two series-connected TVGs are operated in connection modes (C) and (D) in Fig. 2. So it is suitable as an overvoltage protection device in which polarity of the applied voltage is positive or negative.

Disadvantage of two series-connected TVGs is to require two trigger circuits. The trigger circuit requires the withstand voltage higher than that of a single TVG.

\section{3 The effect of the grounding to the switching time}

One of the terminals in the high voltage source is usually grounded. The effect of the grounding to the switching time should be clarified.

Concerning the grounding effect, there are four operation modes for the same mechanical connection mode of two series-connected TVGs as shown in Fig. 11. The neutral point $P$ was floating in mode (C) \pm and $P$ was grounded in mode $(C)^{\prime} \pm$. The operation modes $(C)+$ and $(C)-$ have been previously discussed in section 3.2.

The switching times of modes $(C) \pm$ and (C)' \pm are shown in Fig. 12. The switching time of mode (C) \pm was short and nearly constant approximately 0.3 us at voltage 5 to $25 \mathrm{kV}$. Conversely, when $P$ point was

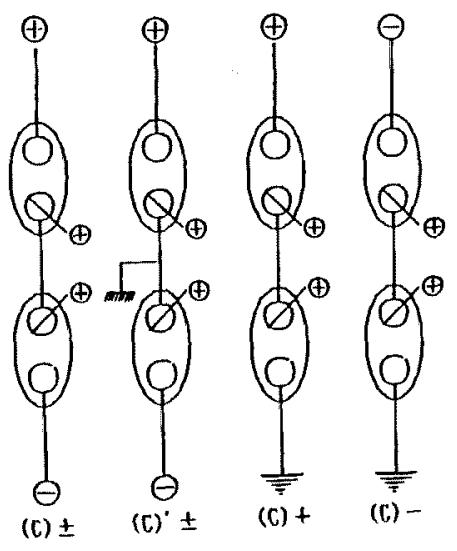

Pig. 11. Four operation modes of two seriesconnected TVGs for the same mechanical connection mode.



Fig. 12. Switching time as a function of main voltage when the neutral point of two seriesconnected TVGs is floating or grounding.

Table 3. Decreasing order of triggering ease.

\begin{tabular}{|c|c|c|c|}
\hline TVG & Order & $\begin{array}{l}\text { Operation } \\
\text { mode }\end{array}$ & $\begin{array}{l}\text { Switchig time } \\
\text { at } 20 \mathrm{kV}(\mu \mathrm{s})\end{array}$ \\
\hline $\begin{array}{l}\text { series } \\
\text { connected } \\
\text { TVG }\end{array}$ & $\begin{array}{l}1 \\
2 \\
3 \\
4\end{array}$ & $\begin{array}{l}(C) \pm \\
(C) \pm \\
(C)+ \\
(C)-\end{array}$ & $\begin{array}{l}0.3 \\
0.6 \\
7 \\
10\end{array}$ \\
\hline $\begin{array}{l}\text { single } \\
\text { TVG }\end{array}$ & $\begin{array}{l}1 \\
2\end{array}$ & $\begin{array}{l}\text { (S) }+ \\
\text { (S) - }\end{array}$ & $\begin{array}{l}0.4 \\
2.7\end{array}$ \\
\hline
\end{tabular}

grounded, the switching time decreased with increasing main voltage.

When the aeutral point $\mathrm{P}$ in Fig. 6 was floating and the upper TVG broke down, the applied main voltage on the lower TVG was 2 times greater than when $P$ was grounded so that breakdown of two series-connected TVGs occurred fast.

When the neutral point $P$ in Fig. 6 was grounded, the main voltage is equally divided into each TVG, therefore the switching time was longer than that of mode (C) \pm . The effect of the grounding to the switching time is summarized in Table 3.

\section{Conclusions}

The switching characteristics of two series-connected triggered vacuum gaps have been examined. The main conclusions are as follows.

(1) The impulse withstand voltage of two series-connected TVGs ( the lower TVG was grounded) was about 2 times greater than that of a single TVG. There was no effect of the connection modes upon the withstand 
voltage on both positive and negative polarity.

(2) The polarity effect to the switching time was pronounced. When the lower TVG was grounded and both nonholed electrodes were positive, the switching time of two series-connected TVGs was short and nearly constant ( $1.4 \mu$ s at 5 to $30 \mathrm{kV}$ ). Conversely, when both nonholed electrodes were negative, the switching time was the longest.

(3) When the polarities of both nonholed electrodes were different, the switching time was long.

However, the polarity effect to the switching time decreased.

(4) The effect of the grounding to the switching time is summarized in Table 3 . When the neutral point $P$ of two series-connected TVGs was floating, the switching time was short and nearly constant ( 0.3 us at 5 to $25 \mathrm{kV}$ ).

The authors thank to Mr. T. Itoh for his assistance in conducting the experiments.

( Manuscript received July 15, ' 94 revised March 27, '95 )

\section{References}

(1) T.R.Burkes et al. :"A Review of High-Power Switch Technology", IEEE Trans., Elect. Devices, ED-26, 1401(1979).

(2) Ihor Vitkvitsky:"High Power Switching", Van Nostrand Reinhold Comp. , p. 13(1987).

(3) G.Schaefer et al.:" Gas Discharge Closing Switches ", Plenum Press, p. 1(1990).

(4) T.Harada et al.:" Handbook of High-Current Engineering ", Corona Publishing Co. LTD, p. 160(1992).

(5) E.Kuffel and M.M.Bera:" Breakdown in Triggered Spark Gaps in Air ", IEEE Trans. Pow. App, and Syst.PAS-87, 1628(1968).

(6) P.F.Willam and F.E.Petekin:" Triggering in trigatron spark gaps : A fundamental study ", J. Appl. Phys. 66, 4163(1989).

(7) J.M. Lafferty:" Triggered Vacuum Gaps" , Proc. IEEE, 54, 23(1966).

(8) T.Harada et al.:" Development of a New High Quality Impulse Vol tage Chopping System ", Trans. I.E. E. Japan, 96-B, 421(1976).

(9) T.M.Parnell:"A Triggered Chopping Gap for Use in Transformer Testing ", IEEE Trans. Pow. App. and Syst., PAS-87, 1885(1968).

(10) S.Schneider and G.W. Talor:" Transient in High-Power Modulators ", IEEE Trans. Elect.Devices, ED-13, 977(1966).

(11) N.S.Nichol is et al.:" Doble-Ended Hydrogen Thyratrons for Crowbar Protection of High-Power TWT Systems", IEEE Trans. Elect.Devices, ED-26, 1456(1979).

(12) S.Schneider et al.:" Multiple-Electrode Triggered Vacuum Gaps ", IEEE. Trans. Elect. Devices, ED-16, 293(1969).

(13) K. Itagaki et al.:" Characteristics of Triggered Multistage Vacuum Gap ", Trans. I.E.E. Japan, 107-A, 193(1987).

(14) K. Itagaki et al.:" Impule Breakdown Voltagees of Triggered Multi-stage Vacuum Gap ", Trans. I.E. E. Japan, 110-A, 684(1990).

(15) 1.Hayashi and Y.Seno:" Swiching Characteristics of Air Gap Swi tches and Vacuum Switches", J. I.E. E. Japan, 86-4, 58(1966).

(16) G.A. Farral:" Low Voltage Firing Characteristics of a Triggered Vacuum Gap", IEEE. Trans., Elect. Devices, ED-13, 432(1966).

(17) R. L. Boxman:" Triggering Mechanism in and Breakdown Delay in
Triggered Vacuum Gaps ", IEEE Trans, ,Elect. Devices, ED-24, 122 (1977).

(18) A. J.Green and C.Christopoulos:"Plasma Build up and Breakdown Delay in a Triggered Vacuum Gap ", IEEE Trans., Plasma Sci., PS-7, 111(1979).

(19) F.T.Warren et al.:" Vacuum Switch Trigger Delay Characteristics", IEEE Trans., Plasma Sci.,PS-10,298(1982).

(20) V.A. Vozdvijensky and V.A.Sidorov:"Initial Stage of Discharge Current Growth in a Triggered Vacuum Gap", IEEE Trans., Plasma Sci., 19, 778(1991).

(21) K. Itagaki et al.:" Seald-off Triggered Vacuum Switch for Pulse Currents", Trans. I.E. E. Japan, 94-A, 220(1974).

(22) IEEE Standard Techniques for High-Voltage Testing, IEEE Std. 4-1978.

Hazairin Samaulah (Student Member) He received


his M. Eng. degree in electrical engineering from Niigata University in 1994. He is currently in the postgraduate program, and is researching discharge phenomena in vacuum such as TVG and its application.

Kouichi Itagaki (Member) He received the B.Eng.

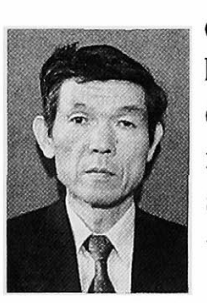
degree in electrical engineering from Ni igata University in 1962 and D. Eng. degree from Tokyo Institute of Technology in 1978. He became an Assistant, Associate Professor and a Professor at Ni igata University in 1965, 1977 and 1985 respectively. $\mathrm{He}$ is engaged in research on vacuum discharge and wind power engineering. He is a member of Japan Wind Energy and Japan Society of Snow Engineering.

Hiroshi Kitamura (Member) He received the B. Eng.

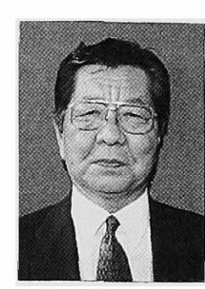
degree in electrical engineering from Ni igata University in 1956 and D. Eng. degree from Tokyo Institute of Technology in 1970. He became an Assistant, Associate Professor and a Professor at Niigata University in 1955 , 1964 and 1975. He is engaged in research on discharge phenomena in air and gas.

Akira Sugawara (Member) He received his Ph. D.

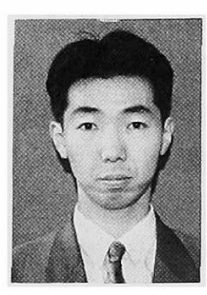
Eng. degree from Ni igata University in 1994. In 1994 he joined Niigata University as an Assistant and is engaged in research on TVGs and applications. He is a member of The Physical Society of Japan and The Japan Society of Plasma Science and Nuclear

Fusion Research. 